\title{
Distal myopathy
}

INSERM

\section{Source}

INSERM. (1999). Orphanet: an online rare disease and orphan drug data base. Distal myopathy. ORPHA:599

Distal myopathy refers to a group of muscle diseases which share the clinical pattern of predominant weakness and atrophy beginning in the feet and/or hands. 